\title{
Systemic genre-and-style relations in the english-language student academic essay: paradigmatics, sintagmatics, epidigmatics
}

\author{
Sergei Nikolaev ${ }^{1}$, Marina Sukhomlinova ${ }^{1, *}$, and Svetlana Nikolaeva $^{1}$ \\ ${ }^{1}$ Southern Federal University, Bolshaya Sadovaya, 105/42, Rostov-on-Don, 344006, Russia
}

\begin{abstract}
This work is focused on the problem of genre specificity within the English language academic discourse of today. The goal of the research is to reveal and analyze system relations regularly and steadily showing themselves within one definite genre of the student essay, their significance and role in the official university communicative space. The abovesaid relations can be found at both the structural level, i.e. in the special text arrangement of essays, and at the conceptual level of the genre. The basic investigation methods are: interpretation and classification of the material; linguistic observation and description; componential analysis of dictionary definitions; comparison and contrasting; linguistic, functional and stylistic, genre analysis of the text; context and discourse analysis; argumentative illustration tool. The practical value can be viewed as a possibility to apply the investigation results in teaching; e.g. during the courses of English, language culture studies, linguadidactics, cross-cultural pragmatics. The authors conclude that student essay text demonstrate closely interweaving paradigmatic, syntagmatic and epidigmatic links. Paradigmatics is represented by semantic and conceptual categories of systemity, integrity, cohesion and closeness. Discourse syntagmatic categories are characterized by linguosemantic consistency, linearity, remoteness, parallelism. Epidigmatic systemity can be traced as the availability of derivative words.
\end{abstract}

\section{Introduction}

\subsection{Topicality}

The growing role of science in the modern world leads to linguistic research in academic writing genres. Academic texts being the final product of research are not the only focus of attention but also the process of their creation [1]. To create a text correctly, a university student must show academic literacy. Literature demonstrates that academic literacy is a complex, multi-faceted and discipline-based phenomenon [2]. The concept of academic literacy can be defined as the ability to translate academic written discourse on

\footnotetext{
*Corresponding author: sukhomlinovam@mail.ru
} 
the basis of foreign language professionally oriented academic texts, think critically, and increase one's self-educational competence for educational and professional purposes [3].

The academic essay is considered as an academic discourse genre which has gained a special importance today due to it being part of university education and the international exam format (IELTS, TOEFL, CAE, CPE). It means that the number of potential producers of this kind of text is not limited to university undergraduates. On the contrary, among them are candidates with a degree that are taking a language exam to certify their level to further get a chance to be employed or enrolled in another university course abroad as well as language and teaching experts (majoring in English) willing to certify or improve their qualification.

All the abovesaid means that the academic exam essay, while being popular with a wide audience, is supposed to have a developed market of experts properly qualified and experienced to teach the academic writing skill as well as that of exam essay check. Professional training of such experts can be considered an allied area.

Meanwhile for teachers to obtain an adequate approach to teaching the technique of essay writing together with a clear idea of essay requirements it is essential to analyze the academic essay text as a complex manifold construct. The latter is an open system of genre and stylistic relations. Essay analysis from this standpoint reveals relations referred to three major areas - paradigmatics, sintagmatics, and epidigmatics. Inability to take those relations into account (in terms of teaching) and their violation (in terms of writing) theoretically and practically, - lead to insufficient or negative results. The relevance of the stated topic, its theoretical and practical value stem from all the above-mentioned ideas.

\subsection{Definitions of the Key Notions}

It is generally accepted that we speak (orally or in writing, expressing our thoughts) specifically within the framework of speech genres (M.M. Bakhtin). A speech genre is a communicative entity characterized by a number of features: a definite communicative situation, expressiveness, contact between the units ща expression and the reality, availability of the addresser concept and, apart from this, the addressee concept, etc. A speech genre is embodied and manifested in the text perceived as a special succession of language signs whose major characteristics are connectedness (this being provided by text cohesion and text coherence) and integrity (I.R. Galperin). A total of texts steadily functioning within a genre, makes a discourse, that is communicative event that is simultaneously both speech as a process and speech as a result.

The fundamental notion of a discourse is treated by us as oral, written and/or online communication expressed by a total of thematically, culturally and socially interconnected and interdependent texts which are embodied in variable, yet related to each other forms of expression (compare to the well-known definitions given by linguists, literary scholars, experts in text theory and discourse theory).

All participants in the academic discourse stay within in the communicative space of the university environment, in which the educational process in all its variability is carried out. This variability is manifested both in the variety of forms of training, and in extracurricular activities. Students are focused on receiving quality education, which is the main value of academic discourse; teachers focus on the process of transmitting knowledge and personal education. Thus, we consider academic discourse not only as a product of activity, but also as a dynamic process of its achievement (creation), which is determined by a number of external and internal factors [4].

From the productive side of communication (the author's position), discourse is understood as the process of encoding information in accordance with lexical, grammatical and syntactical rules, taking into account the stylistic, genre, social, cultural, psychological 
and emotional factors, with the use of cohesion and coherence in order to achieve a communicative goal - to convey information to the recipient. From the receptive side of communication (the recipient's position), discourse is the process of decoding information [5].

Now let us give a detailed description of the genre of academic essay, whose contents, rules of preparation and writing vary according to the academic field within which this type of a written text is being produced. During the lifetime of universities, there appeared a general algorithm of writing academic essays, this algorithm containing both unified and differential stages of its creation within various academic subject areas. It should be noted that an essay needs serious preparation expressed as reading a lot in this or that topic and theme. At the same time, one must take a critical look of the content and quality of the material. An academic essay, alongside an academic lecture and an academic article, is a learned paper. This text is created by the student with regard to the material of the lectures he has listened to, yet largely backed by scholarly papers. This is, apart from the rest, due to the fact that very few lecture texts become accessible, there it is difficult to make references to these or give a verbatim quote. In this sense articles are a reliable information provider. Target readers of an academic essay are the teacher that has given this task or the examiner in case the essay is to be written aa a part of an international exam. If the essay is to be read aloud, all the students also turn into listeners. Thus, the genre of an essay promotes direct or indirect two-way communication.

\subsection{Classification}

Since this investigation is focused on the English-language academic discourse of today, there is a necessity to review, at least briefly, the system of genres in which this discourse is embodied. All this discourse variety can be subdivided into two large groups of genres. On the one hand, these are the genres referred to education and pedagogic, and on the other hand these are those referred to the field of research. Among the written genres of the first group (which we are concerned with), noted may be lecture notes, a term paper and a graduation paper, a practical training report and a lab research report, just to name the major ones. Special position among other written genres is taken by the student essay genre (see Table 1).

Table 1. Genres, constituting a modern English-language academic discourse.

\begin{tabular}{|l|l|l|l|}
\hline \multicolumn{4}{|l|}{ Educational and pedagogical academic genres } \\
\hline Oral & Written & Hybrid & Electronic \\
\hline Lecture & lecture notes & presentation & Web-based project \\
\hline tutorial & project & project & $\begin{array}{l}\text { course books and } \\
\text { tutorials }\end{array}$ \\
\hline seminar & $\begin{array}{l}\text { yearly paper, } \\
\text { term paper }\end{array}$ & $\begin{array}{l}\text { valedictory } \\
\text { speech }\end{array}$ & $\begin{array}{l}\text { scientific and scientific- } \\
\text { popular articles }\end{array}$ \\
\hline exam & exam paper & & dictionaries \\
\hline faculty survye & graduation paper & & peer reviewing \\
\hline credit & credit & & e-mails \\
\hline defense of the thesis & seminar paper & & faculty survey \\
\hline $\begin{array}{l}\text { students' scientific } \\
\text { conference }\end{array}$ & practical training report & & video presentation \\
\hline practical class & lab research report & & webinar \\
\hline consultation & grant proposal & & online lecture \\
\hline valedictory speech & dictionaries & & online consultation \\
\hline students' forum & $\begin{array}{l}\text { scientific } \\
\text { scientific-popular }\end{array}$ & & university web-page \\
\hline
\end{tabular}




\begin{tabular}{|c|c|c|}
\hline & articles & \\
\hline \multirow[t]{11}{*}{ laboratory research } & $\begin{array}{lll}\text { course } & \text { books } & \text { and } \\
\text { tutorials } & & \\
\end{array}$ & video tutorial \\
\hline & essay & videoconference \\
\hline & academic portfolio & academic video journal \\
\hline & $\begin{array}{l}\text { review of academic } \\
\text { literature }\end{array}$ & \\
\hline & peer reviewing & \\
\hline & academic journal & \\
\hline & $\begin{array}{l}\text { academic } \\
\text { correspondence }\end{array}$ & \\
\hline & academic memo & \\
\hline & lesson plan & \\
\hline & course documentation & \\
\hline & faculty survey & \\
\hline
\end{tabular}

Contemporary English-language educational system practices include writing essays of the following two basic types:

1) a college admission / application essay;

2) an academic essay / paper.

The latter type falls into a training (current or final within the academic curriculum) essay and an exam essay (making part of the international exam, its Writing section).

\subsection{Historical Background}

The term essay was borrowed by English from French (essai - Fr. endeavor, try, experience, outline, draft), which in its turn borrowe the notion from Latin (exagium - Lat. weighing). As a separate written genre form, the notion of an essay was introduced by Michel de Montaigne in his Essais in 1580. This term was first used in English literature by Francis Bacon in his papers in 1597, 1612 and 1625.

The academic essay genre appeared together with the establishment of European universities at the 18th century end. Originally the essay was a solely literary genre which had budded from the genre form of La Satire Ménippée and Socrates dialogues. Historical reasons of this genre appearance were the social and political changes taking place in Europe during the Renaissance, namely the spring and development of bourgeoisie as a class and those social and psychological (worldview) shifts in the mass consciousness of the Renaissance: fall of the theocentric world model and its replacement with the anthropocentric (scientific) one.

\section{Materials \& Methods}

As the material, we selected seven academic essays belonging to different fields of knowledge: medicine - "Investigating the level of VEGF in two different chronic nephropathy models" (available at: https://www.ukessays.com/essays/medical/investigating-the-level-of-vegf.php, access date: 2017.03.2021), physics - "Importance of Physics in our Daily Life Essay" (available at: https://www.ukessays.com/essays/sciences/the-role-of-physics-in-our-daily-lives.php, access date: 19.11.2017), social science - "Social Stratification and Class" (available at: https://www.ukessays.com/essays/sociology/what-is-meant-by-social-stratification.php, access date: 18.11.2017), methods of teaching - "What Makes a Teacher Effective?" (available at: https://www.ukessays.com/essays/teaching/makes-teacher-effective-8920.php, access date: 19.11.2017), technology - "Negative Effects of Technology on Society" 
(available at: https://www.ukessays.com/essays/technology/negative-effects-of-technologyon-society.php, access date: 17.11.2017), environment - "Impact of Human Activities on Earth" (available at: https://www.ukessays.com/essays/environment/impacts-of-humanactivities-on-the-earth.php, access date: 19.11.2017), as well as an essay with the elements of discussion based on the student's own experience - "A day in the life of a university student" (available at: https://www.oxbridgeessays.com/blog/day-life-university-student/, access date: 15.11.2017).

The subject, goal and objectives of the investigation have stipulated the choice of the complex use of the following methods: interpretation and classification of the material; linguistic observation and description; componential analysis of dictionary definitions; comparison and contrasting; linguistic analysis of texts; functional and stylistic analysis; genre analysis; context and discourse analysis; argumentative illustration tool.

\section{Results \& Discussion}

The academic essay is aimed at:

1. Demonstration of deep knowledge on the topic, this knowledge based upon research and studies of scientific and popular scientific literature.

2. Critical reflection on and assessment of the essay basic topic to a limited extent. The author concentrates not on the description, but rather on the "development" of intellectual arguments and analysis of scientific ideas.

In the academic essay the producer uses and reexamines information he has obtained during lectures and seminars, as well as while reading scientific and popular scientific literature.

The volume of the academic essay may be close to the volume of an academic article, while during international exams its minimum size is 250 words.

Let us now watch the interlinked systemic connections using the example if seven academic essays belonging to different areas: medicine, physics, social science, teaching methods, technology, environment, as well as an essay with the elements of discussion based on the student's own experience.

Practically all the discussed academic essays are logically drawn out and well structured, i.e. subdivided into sections, each under its own title, depending on their contents. Generally, an essay consists of a Title, probably formulated as a question; an Introduction; a Body; and a Conclusion. The Body always falls into several sections which often have affirmative titles like "Negative Effects of Technology", "Cutting fruits and vegetables", "9-12 Lectures in the lecture hall", etc. However, the titles to the sections may also be expressed as questions. Thus, the Body of the essay "What Makes a Teacher Effective?" has sections with the following titles "What do you think it means to be an 'effective' teacher?", "Why do teachers need to purposely plan for learning?", "How can effective teachers best engage students in learning?", "Why is developing positive communication skills important for effective teachers?", etc. A section title sometimes ends with an exclamation mark, which speaks for the author's enhanced emotionality, e.g.: "8.30am (or later if you are an arts student!!). Breakfast in the cafeteria".

Judging by the samples of English language academic essays, their titles typically meet the general demand of laconic brevity. In some areas of knowledge, essays contain many references and are followed by the Works Cited section, which is obligatory with most universities. Compliance to this regulation helps the reader better understand the bases to the author's facts, arguments and conclusions. However, some separate works contain neither the former, not the latter. According to our reckoning, this might speak of the following: a) the student showed lack of responsibility while fulfilling the task of writing a quality academic essay; b) the student excels at the topic and shares his own experience. 
Text generation is believed to be a result of systemic discourse processes, while the academic text itself is a basis unit of the academic discourse. The process of the academic essay production involves a use of referential materials, as well as active wok with scientific and popular scientific literature. It is important to note that specifying the audience of a text before the process of writing creates this opportunity for the students to consider the needs and expectations of that audience and therefore discuss their ideas in a way that facilitate interaction between them [6, p.1022].

Let us try to describe systemic paradigmatic, syntagmatic and epidigmatic relations present in students' academic essays. The combinability of words is navigated by the consciousness of the native speaker. It plays a major role in a process of formation of utterances and provides for the natural verbalization of thought in by means of semantically and structurally related words. Transformation of syntagmatic structures involves complex paradigmatic elements or structures of utterances, which represent the most challenging constructions and cause additional cognitive efforts [7, p. 64]. It is worth reminding that paradigmatic relations in discourse are represented by such semantic and conceptual categories as systemacity, integrity, coherence, closeness. Text systematicity of the studied academic essays manifests itself as orderliness of all the sections: the text always starts with an introduction and ends in a conclusion (or References). Any change of this section order is impossible. Text integrity highlights the inner unity of all of its structural parts, which for example shows itself through the use of linking words: however, moreover, in short, firstly, secondly, for example, thus, so, hopefully, to sum up, wrapping up, to expand the above statement, as we know, to detail the above contention, as a matter of first importance, for instance, nonetheless, case in point, at last, and more. Along with that, there are "signals of transition" from one logical part to the next one:

So, in the present study we decided to (points at the introduction) investigate the level of $V E G F$ in two different chronic nephropathy models; one was diabetes induced chronic nephropathy and the other was non diabetic nephropathy.

We thus hypothesize (points at hypothesis put forth subsequently) that differential expression of VEGF in diabetic and non-diabetic kidney diseases is mediated by $A_{2 B} A R$ [8].

Here are our top tutorial tips (points at the advice that follow) [9].

Here we will discuss (points at the problem discussion that follows) how physics is playing its part in running our everyday tasks and assists us to do our errands, chores and duties smoothly and effectively [10].

The category of integrity of the academic essay implies its inner unity manifesting itself the logic, structure and wholeness of the text. The categories of integrity and unity show themselves through the nominative correlation with some real world fragment. Thus, the text of the essay acts as the significatum (sign, designation) to an extra-linguistic real life event, while its constituents are those uttered sentences actualizing their nominative function.

Still another semantic and conceptual paradigmatic category is most probably closeness, which in a certain way overlaps the notion of completion of the author's message. The category of closeness points at the fact that this definite discourse does not permit any language means out of relation to the topic of the discourse.

Now let us turn our attention to those other language means that most vividly actualize paradigmatic relations within the text of the academic essay (see Table 2). 
Table 2. Linguistic means that actualize paradigmatic relations in the text of an academic essay at the lexical and grammatical levels.

\begin{tabular}{|c|c|}
\hline Name & Example \\
\hline General scientific lexis & knowledge, method, effect \\
\hline Specialized (terminological) lexis & subclinical diagnoses, diabetic nephropathy \\
\hline University academic lexis & lectures, supervisions, tutorial sessions \\
\hline Abstract lexis & complications, competence, view \\
\hline Abbreviations & $\begin{array}{c}\text { DN (Diabetic nephropathy), } \boldsymbol{R} \boldsymbol{A S} \text { blockade, } \\
\boldsymbol{V E \boldsymbol { E } F} \text { effects }\end{array}$ \\
\hline Compound words & $\begin{array}{l}\text { age-adjusted, day-to-day, audio-visual, } \\
\text { group-organised, professor-led }\end{array}$ \\
\hline Numerals & type 1 and type 2 diabetes \\
\hline Formulas & $a=F / m$ \\
\hline Phraseological units and set expressions & $\begin{array}{c}\text { to cause effects, to play an important role, to } \\
\text { meet the (learning) goals, to set foot on } \\
\text { ground, to spark interest, taking in } \\
\text { consideration, to face a problem }\end{array}$ \\
\hline Antonyms & $\begin{array}{c}\text { non-diabetic and diabetic, the dark side and } \\
\text { the bright side }\end{array}$ \\
\hline Lexical repetitions & $\begin{array}{l}\text { Social stratification works by society } \\
\text { ranking which is based in four sections. } \\
\text { Social stratification can be passed from one } \\
\text { generation to the next ... }\end{array}$ \\
\hline Elements of enumeration & $\begin{array}{l}\text { Physics is considered natural science } \\
\text { because it deals with the things like matter, } \\
\text { force, energy and motion. }\end{array}$ \\
\hline Comparisons and contrasts & $\begin{array}{c}\text { in contrast, similarly, to be more agreeable } \\
\text { than before }\end{array}$ \\
\hline Metaphors & $\begin{array}{c}\text { the academic frontline, generate a negative } \\
\text { environment }\end{array}$ \\
\hline $\begin{array}{l}\text { Modal verbs, modal words and particles, } \\
\text { introductory words, state words }\end{array}$ & hopefully, exactly, may, might, should \\
\hline
\end{tabular}

From Table 2 it follows that such relations can be traced, among other factors, in the availability of:

1. Abbreviations, e.g.:

Diabetic nephropathy (DN) is the most common cause of ESRD development among other disorders predisposing to ESRD [8].

This example shows that abbreviations are used both separately and as parts of word collocations.

2. Compound words, e.g.: age-adjusted, day-to-day, audio-visual, group-organized, professor-led, hit-and-miss, amphitheatre-like, faculty-organized. E.g.:

One big piece of advice seems to be that vegetarians are often better off going for the self-catering option, as almost all reports suggest a distinct lack of variety and quality to university-provided veggie options [9]. 
3. In the same way as with the texts of the genres of lectures and articles, essay texts also contain general scientific lexis; specialized words, or terms; abstract lexis; as well as academic university lexis, e.g.: But despite knowledge (general scientific lexis) of the devastating effects (general scientific lexis) of these complications (abstract lexis) and the involved costs to patients, to date, there is still no method (general scientific lexis) that is sufficiently sensitive and accurate for subclinical diagnoses (terms) of diabetic nephropathy (terms) [8]. Unlike school where lessons are scheduled throughout the day, at uni (abbreviated name of a university) you are more likely to have a few lectures, supervisions and tutorial sessions (academic lexis) scattered through the week [9]. As these examples show, terms may be used both all by themselves and alongside nonterminological words.

4. Numerals used both independently and within collocations, e.g.:

Moreover, RAS blockade is usually initiated only after DN manifests itself clinically with persistent proteinuria in both type 1 and type 2 diabetes [8].

5. Formulae, e.g.:

Second law of motion states that $\boldsymbol{a}=\boldsymbol{F} / \boldsymbol{m}$ i.e. acceleration is directly proportional to the force we use or exert while walking, therefore, when we will apply more force, our acceleration will increase [10].

6. Set expressions, e.g.:

$E G F$ and NO interaction has been explained as one of the regulating mechanism in causing paradoxical effects of VEGF by Takahiko Nakagawa et al.; 2007 [8].

Academic essay texts also contain set expressions demonstrating various levels of semantic integrity like: it's all fun and games, to meet the (learning) goals, to meet outcomes (in a Passive Voice (learning) outcomes can be met), to set foot on ground, to take place, to spark interest, taking in consideration, to face a problem, and some others.

7. Antonyms, e.g.:

The contrasting effects of VEGF in non-diabetic and diabetic kidney disease prompted us to review factors modulating VEGF expression in CKD [8].

The author explained the dark side and the bright side of VEGF effects [8].

Physics is also involved in opening and closing of hinged doors. The phenomenon involved in opening and closing of door is torque [10].

8. Word repetitions, e.g.:

Social stratification works by society ranking which is based in four sections. Social stratification can be passed from one generation to the next, i.e. royalty, it is universal but varies over time and place, it is a trait of society not individual differences and lastly social stratification also goes on beliefs and not just inequality (Wikipedia, 2014) [11].

9. Enumerations, e.g.:

Physics is considered natural science because it deals with the things like matter, force, energy and motion [10].

Substantial movement, air contamination, long of timberland, boundless chase of creatures are the most genuine issues that our planet confront these days [12].

1. Comparisons, e.g.:

Similarly, when light falls on black object it absorbs all the light and reflects nothing that's why that object looks black (Pappas, 2010) [10].

Life appears to be more agreeable than before with progressed machines, we have less opportunities to approach the nature [12].

2. Metaphors, e.g.:

If a teacher builds a positive relationship with their students there is a direct influence on the type of communication they will engage in, positive relationships opens a positive environment and negative relationships will generate a negative environment (Howell, 2014) [13]. 
We must also refer modality cases to the paradigmatic relations of the English language academic essay. Subjective or author's modality is among the universal categories of the academic text, represented at various language levels, lexico-grammatical and syntactical levels included. Modality of this type reflects the author's attitude to reality through the text contents. Language modality representations of the English academic text include modal verbs, modal words and particles, parenthetic words, words of the category of state; this scholar provides their frequency analysis. E.g.:

The introductions should always be related to the topic and spark interests (Whitton et al., 2016) [13].

A person in a class system may also start off in one class but can move between classes (Spark Notes, n.d) [11].

The English language academic discourse contains both general textual categories and discourse syntagmatic categories. The first group includes verbal, semantic and structuralsyntactic categories, which means that the text contains interacting lexeme penetration, theme-and-rheme explication and syntagmatic succession of sentences. The second group includes linguo-syntagmatic succession, linearity, remoteness and parallelism. Of greatest importance for our investigation is the second group of categories. Let us now consider these one after another. Generally speaking, linguo-syntagmatic succession is viewed as a one-by-one consecution of units. The category of discourse succession presupposes repeated marking, in the lexemes and sentences, of the already named object; meanwhile syntactical units within theme-and-rheme positions consistently change places in utterances [14].

Let us consider the above specificities using definite examples from academic essays:

The current therapy for patients with renal injury includes glycemic control by antidiabetic medications. Blockage of renin angiotensin system (RAS) is the most commonly practiced way of controlling blood pressure in DN [8].

In our opinion, the theme, i.e. the familiar information contained in the first sentence, is «The current therapy for patients with renal injury», while its rheme, i.e. the unfamiliar, new information, the initial point of the utterance, is "glycemic control by antidiabetic medications". One may assume that the "controlling" of the second sentence is the "system blockage"; then is fact the rheme turns into the theme of the successive utterance. However, after analyzing quite a number of academic essays, we failed to notice such a regularity. In the following sentence the author quite often provides further development to the theme and introduces new characteristics of the matter in dispute. Hence this matter may be highlighted in two or even three successive sentences. E.g.:

Diabetic nephropathy (DN) is the most common cause of ESRD development among other disorders predisposing to ESRD. The costs of DN are significantly higher than those from other diabetic complications because the patients are subjected to haemodialysis programs and renal transplant when failure occurs. Thus, the burden of DN on public health is enormous [8].

In the above case, the terminological collocation diabetic nephropathy (DN) is the theme, and the expression the most common cause of ESRD development is the rheme, to be more precise the rheme nucleus. In the next sentence, the theme is the expression The costs of $D N$ since this is a new characteristics that has not been mentioned in the first sentence; the rheme nucleus is the word higher. In the third sentence, the theme is the phrase the burden of DN on public health, while its rheme is the word enormous.

The next discourse-syntagmatic category is sense linearity. This presupposes text expansion, as well as availability of the beginning, the continuation and the logical ending of the piece. The thematic focus on a definite domain is highlighted in the very beginning, it tunes all the content and must be followed throughout the whole text. The theme of the individual utterance in discourse is stipulated by the way in which its information is linearly 
distributed, while the discourse rheme points at the way its content is organized globally and hiararchically [van Dijk 1981: 190; compare: Dridze 1984]. All the academic essay texts analyzed by us contain the category of linearity. Thus, the essay named "What Makes a Teacher Effective?" starts with the following sentence:

An effective teacher utilises aspects of their background, professional knowledge and personality to boost students' academic growth (Whitton, Barker, Nodworthy, Sinclair, Phil, 2004).

The conclusion to the same essay reads:

An effective teacher will aim to promote a positive learning environment through means of displaying approachability and showing assertiveness in their communication. Assertiveness is categorised as communication style as well as aggressiveness and passivity (Howell, 2014). A good teacher will avoid aggressive and passive styles in communicating as they foster a negative learning environment but should focus on being assertive. The assertive teacher will display the capabilities to be an effective active listener; nonjudgemental; able to express himself with honesty; respect others' values; able to check on others' feelings, all while being proactive, flexible, trustworthy and confident (Howell, 2014) [13].

Thus, the semantic focus is strictly followed during the whole essay text.

Another discourse syntagmatic category is remoteness which is traditionally viewed as a "break" between the communicating parties (subjects of the discourse) in time and space, in spite of the fact that the academic essay is by its communicative nature interlocutory. The essay of this type is intentionally written to be later checked by the professor whose objective is to assess the accumulated knowledge and experience of the student, as well as his ability to reflect on the given topic and present his ideas adequately and properly. The producer in this genre is the student, while the recipient is the teacher.

Still another discourse syntagmatic category is syntactical parallelism in which the members of the syntactical structure do not show interdependence, yet their syntactical links overlap. The use of this device is meant to enhance the subject of the description making it more important and vivid. At the same time there might be parallels between those sentences (or structures) located both close to each other and at a distance. E.g.:

Social classification has taken place long before the modern form of classifying people began. Social stratification has been measured in different forms; from asking people which class they feel they belong in to using a person's postcode [11].

In these sentences, lexemes classification and stratification may be viewed as synonyms.

Here is another example:

When we apply force perpendicular to the door, larger angular acceleration is produced. When we apply force on the door knob, compel the door to rotate on its axis thus acting on the principle of torque [10].

In the sentence "Seminars are like a stepping-stone between lectures and tutorialsthey typically involve around 30-50 students and are professor-led, but can also include some rich and diverse student involvement and debate" [9], syntactic parallelism shows itself in the fact that seminars are equaled to stepping-stones, an interim option between lectures small group work; in other words, there is an antithetic parallel seminars - lectures and seminars - tutorials. At the same time the sentence tells the reader that seminars involve from 30 to 50 students and are guided by professors, i.e. there is an evident parallel between the phrases seminars - involve around 30-50 students and seminars - are professor-led. Here is another example:

Planning is an important technique teachers use to amplify student achievement as well as teacher satisfaction, the best teachers are able to organise and deliver the best learning experience through thoughtful planning [13]. 
In this sentence, parallel associations are established between the lexeme technique and phrases to amplify student achievement and teacher satisfaction. The author shows that the planning technique may both improve the student's academic progress and give the teacher satisfaction. In other words, phrases to amplify student achievement and teacher satisfaction are motivated by the lexeme technique.

Now we will turn to a brief description of epidigmatic (in D.N. Shmelev's terms derivational) relations in academic essay texts. It is due to this type of connections within one text and then within one discourse that words and word collocations of various lexical semantic groups are connected to solve a definite communicative task. Epidigmatic systemity of lexis is manifested in the availability derivative words, e.g.: social sociologists - society, equal - inequality, class - classification, measure - to measure, privacy-deprivation, to understand-understanding. At the same time derivatives may not just be located at a distance from each other, but also make collocations. E.g.:

A starting point for an effective teacher is to understand that learning is based on understanding the concept of the content, and the means of an effective teacher is to motivate learners from a state of not understanding to deeper understanding (Killen, 2013) [13].

Sociologists argue that some form of social stratification occurs in every society in the world despite that everyone claims to want an equal society (Burton, 2013) [11].

Besides, as one can see in the first sentence, one and the same derivative word may be used both independently and with an attribute: understanding - deeper understanding.

As the examples show, when people are producing texts, they are not only doing writing-presenting ideas in textual form, but are also writers creating a variety of meanings in the writing context [16, p. 1493].

It should be noted that, in the process of semantic derivation and due to the appearance in the lexeme of a new meaning, the semantic content of the resulting derivative words may either exceed the boundaries of the subject matter or, still functioning within the framework of the existing value paradigm, change its estimation to the opposite one [17, p. 17].

Distribution and character of lexeme actualization within the context is not the same as it depends on the lexeme valency. Let us consider two sentences:

Privacy problems are considered as one of the critical issues. Privacy issues are concerned with tracking locations and spying on information [15]. The lexeme privacy means 1. the state of being alone and not watched or disturbed by other people; 2. the state of being free from the attention of the public [18, p. 1200]. Both sentences actualize the primary, basic meaning of the noun privacy being here an attribute. The word problem is defined as follows: " 1 . a thing that is difficult to deal with or to understand; 2 . a question that can be answered by using logical thought or mathematics" [18, p. 1202]. Hence, in the above example this lexeme is actualized in its primary meaning. Lexeme issue has 6 meanings, including: topic of discussion, problem/worry, magazine/newspaper, stamps/coins/shares, making available/known; children [18, p. 824]. In our example the meaning problem/worry is actualized, which turns lexemes problems and issue into synonyms. We believe that in cases like this syntagmatic and epidigmatic links are especially closely interweaved.

Male and female students tend to use different word groups to write essays. Men tend to use language to convey information or facts, whereas women tend to use language to develop a rapport with other people. Male students use more nouns related to certain social and economic activities and scientific phenomena associated with a topic. Female students, on the other hand, use more personal pronouns and certain words related to psychological cognitive processes [19].

An argument consists of several components. It includes a claim that is supported or attacked by at least one premise. The claim is the central component of an argument. It is a 
controversial statement that should not be accepted by the reader without additional support [20].

Argumentation is a crucial aspect of writing skills acquisition. The ability of formulating persuasive arguments is not only the foundation for convincing an audience of novel ideas but also plays a major role in general decision making and analyzing different stances [21].

There are different schemes of argumentation. For example, argument from cause to effect is a commonly used scheme in everyday arguments [22]. Comprehensively understand an argument or even a part of it is not an easy task. It requires the reader to understand each word that builds the sentence or part of an argument itself. Not only to understand each word meaning, but also understand the relation between one word and another [23].

Ch. Stab and I. Gurevich distinguish between three main approaches to finding arguments based on determining the structure of argumentation in texts in the native language:

- Component identification focuses on the separation of argumentative from nonargumentative text units and the identification of argument component boundaries.

- Component classification addresses the function of argument components. It aims at classifying argument components into different types such as claims and premises.

- Structure identification focuses on linking arguments or argument components [24].

The essence of all the features of the student academic essay as a genre entity are reflected in the allied genre of the academic exam essay. Since the latter is supposed to be written on site and within a limited period of time (40 minutes maximum), it logically cannot be large and contain references - and this is its main difference from the academic essay written as part of a course curriculum. As a result, such an essay is concise, structurally rigid and evidently coherent. Comprehension of an academic exam essay as a structure with a set number of features is reflected in the following assessment criteria:

1. Task Response / Task Achievement.

2. Coherence \& Cohesion.

The Task Response criterion looks at the text as corresponding to the essay question. To get a high band in Task Response it is important to make sure that a) the essay contains answers to all essay questions; b) ideas that are required to cover based on the essay task are covered fully and equally. The latter requirement means that every essay paragraph is to focus on one idea and elaborate it by going deeper and making it more specific. As the exam essay task is normally twofold (e.g.: Why do you think so many children are overweight? What could be done to solve this problem?; What problem has it caused? What solutions can you suggest to this issue?), there are supposed to be at least two body paragraphs answering them. A common question «To what extent do you agree?» also means there will be at least two arguments to support the opinion. Based on that the structure of the relatively short academic exam essay has a more fixed skeleton of elements with limited functions:

- introduction;

- $\quad$ body paragraph 1 ;

- $\quad$ body paragraph 2 ;

- conclusion.

Coherence and cohesion of the text (assessed by the second above-stated criterion) are achieved by:

- lexical repetition of key words (including synonyms) which were used in the essay task;

- repetition of key ideas (signposting) which are consistently expressed throughout the essay in each structural element: claimed in the introduction, elaborated in the body paragraphs and summarized in the conclusion; 
- linkers ensure smooth thought progression;

- pronouns (it is important to make sure there is no ambiguity or unclear referencing).

To reiterate, the exam essay, being characterized by a higher degree of conciseness and, consequently, text structuredness vividly shows genre features of the academic essay.

There is such a variety of academic essays as concept-application essay. When writing this type of essay, the author is required to apply the concept or theory when answering the assignment question. As the overarching rhetorical function of the Concept-Application essay is to show how a concept explains a particular issue or situation, the linguistic resources for explaining are important features of this assignment type [25].

It should be noted that the quality of essay writing is facilitated by formative assessment, which helps the development and formation of the student's personality, as well as a deeper understanding of the material. Formative assessment systems combine teacher, peer and self-assessment diversifies feedback, which allows students to look at their work from different perspectives. They become more responsible through giving peer-feedback and more organized through revision and self-editing [26, p. 488].

\section{Conclusion}

Thus, academic essays belong to the written educational pedagogic genres within the English language academic discourse. Essays can be entrance essays, training essays and exam essays. In English language academic essays, taken into account are such basic parameters as the producer's intentions, volume and academic level of the written piece. In fact, such texts are interlocutory; a two-way communication may be direct or indirect.

Academic essay texts are logically organized and structured. They show closely interweaving paradigmatic, syntagmatic and epidigmatic links. Paradigmatic relations are represented by semantic and conceptual categories of systemity, integrity, coherence and closeness. Relations of this kind are most obviously actualized in the availability a abbreviations; compound words; general scientific lexis, terms, as well as academic university lexis; set expressions; metaphors; modality cases, etc.

General textual categories of English language academic discourse are the verbal category, the semantic category and the structural-syntactic category. All discourse syntagmatic categories are characterized by their linguo-syntagmatic consistency, linearity, remoteness and parallelism.

Epidigmatic systemity of the academic essay lexis can be traced in the availability of derivative words, which promote the fact that within one essay text and subsequently in the academic discourse as a whole words and phrases unite for the purpose of performing a single communicative task.

\section{References}

1. O. Kostrova, M. Kulinich, Procedia - Social and Behavioral Sciences 206, 85-89 (2015)

3. N. Ibrahim, R.M.K. Nambiar, Procedia - Social and Behavioral Sciences 59, 438-442 (2012)

4. N.V. Smirnova, Higher education in Russia 6 (2015) https:/cyberleninka.ru/article/n/akademicheskaya-gramotnost-i-pismo-v-vuze-otteorii-k-praktike

5. S. Nikolaev, M. Sukhomlinova, The European Proceedings of Social and Behavioural Sciences (EpSBS) (2020) 
6. P.V. Sysoyev, I.A. Evstigneeva, M.N. Evstigneev, Procedia - Social and Behavioral Sciences 200, 114-121 (2015)

7. Davud Kuhi, Hassan Asadollahfam, Sara Amin, Procedia - Social and Behavioral Sciences 98, 1016-1025 (2014)

8. M.V. Vlavatskaya, Bulletin of Irkutsk State Linguistic University 3(24), 64-72 (2013)

9. UK Essays. Investigating the Level of VEGF in Two Different Chronic Nephropathy Models (2016) https://www.ukessays.com/essays/medical/investigating-the-level-ofvegf.php

10. Oxbridge Essays. A Day in the Life of a University Student (2010) https://www.oxbridgeessays.com/blog/day-life-university-student/

11. UK Essays. Importance of Physics in our Daily Life (2017) https://www.ukessays.com/essays/sciences/the-role-of-physics-in-our-daily-lives.php

12. UK Essays. Social Stratification and Class (2017) https://www.ukessays.com/essays/sociology/what-is-meant-by-social-stratification.php

13. UK Essays. Impact of Human Activities on Earth (2017) https://www.ukessays.com/essays/environment/impacts-of-human-activities-on-theearth.php

14. UK Essays. What Makes a Teacher Effective? https://www.ukessays.com/essays/teaching/makes-teacher-effective-8920.php

15. A.O. Kalmuratova, Library Information Center of Jalal-Abad State University, http://arch.kyrlibnet.kg/uploads/19\%20A.O.Kalmuratova..pdf

16. UK Essays. Negative Effects of Technology on Society (2017) https://www.ukessays.com/essays/technology/negative-effects-of-technology-onsociety.php

17. M. Rahimivand, D. Kuhi, Procedia - Social and Behavioral Sciences 98, 1492-1501 (2014).

18. A.M. Mubarakshina, Bulletin of TSPU (TSPU Bulletin 9(150), 14-19 (2014)

19. Oxford Advanced Learner's Dictionary (2005)

20. Y. Ishikawa, Procedia - Social and Behavioral Sciences 192, 593-600 (2015).

21. Or Biran,Owen Rambow, International Journal of Semantic Computing 05(04), 363381 (2011)

22. Ch. Stab, I. Gurevych, Proceedings of the 2014 Conference on Empirical Methods in Natural Language Processing (EMNLP), 46-56 (2014)

23. V. Wei Feng, G. Hirst, Proceedings of the 49th Annual Meeting of the Association for Computational Linguistics: Human Language Technologies 1, 987-996 (2011)

24. A. Pradipta Gema et al., Procedia Computer Science 116, 449-459 (2017)

25. Ch. Stab, I. Gurevych, Computational Linguistics 43, 619-659 (2017)

26. G. Myskow, P.R. Underwood, Applying concepts in international relations: The language of causal explanation in high- and low-graded concept-application essays, https://www.sciencedirect.com/science/article/abs/pii/S0889490620300326

27. E.A. Melekhina, K.M. Levitan, Procedia - Social and Behavioral Sciences, 200, 482489 (2015). 